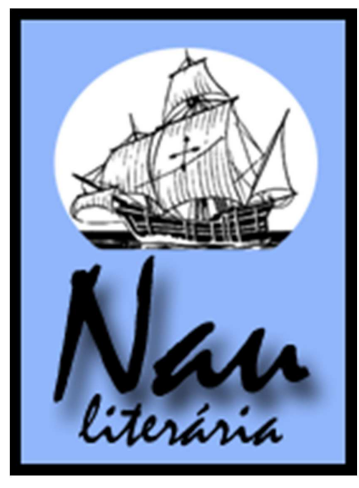

\title{
A dialética entre a Identidade e a Cidade, mediada pela Memória, representada em Mãos de Cavalo
}

\author{
Aline Venturini*
}

\begin{abstract}
Resumo: Propomos, neste artigo, analisar a dialética identitária entre o personagem Hermano da obra Mãos de Cavalo, de Daniel Galera e a cidade de Porto Alegre, considerando a transformação gradual do personagem e do espaço urbano. A mudança sinaliza para um sujeito e uma cidade fragmentadas. O conflito de Hermano é ter visto seu amigo Bonobo ser assassinado e nada ter feito para salvá-lo. Esse tormento o acompanhou durante toda a vida e a possível resolução poderia estar no retorno ao bairro Esplanada, palco do acontecimento, o que propicia uma catarse, que o ajudaria a reviver o que ficou em suspenso durante muitos anos. Ocorre, então, uma espécie de retomada do passado e o confronto do personagem com suas diversas faces e conflitos. $\mathrm{O}$ trabalho estrutura-se a partir de três perspectivas do personagem, quais sejam, a relação entre distância geográfica dele e o bairro Esplanada; o tempo transcorrido entre a infância e a idade adulta e a memória; a consciência na ressignificação do passado. Os sentidos que resultam dessas três perspectivas se dão em função da cidade de Porto Alegre, no bairro Esplanada, quando a personagem completa 30 anos, e, em sua maturidade sente- se capaz de estabelecer relações entre a infância, a juventude e a maturidade, do que decorre a busca do passado, que de certa forma, determina o presente.
\end{abstract}

Palavras-chave: identidade; cidade; memória; consciência.

\begin{abstract}
We propose in this paper to analyze the dialectics of identity between the character Hermano of the novel Mãos de Cavalo, by Daniel Galera and the city of Porto Alegre, considering the gradual transformation of the character and the urban space. The move signals a subject and a fragmented city. The conflict is Hermano seeing his Bonono friend being murdered and having done nothing to save him. This torment followed him throughout his life and the possible resolution could be in the neighborhood return to de Esplanada, the scene of de event, which provides a catharsis, which would help revive what was put on hold for many years. What happens then is a kind of renewed confrontation of the past and character with its many faces and conflicts. The work is structured from the three perspectives of the character, namely, the relationship between his geographic distance and the Esplanada neighborhood; the time between childhood and youth and memory; the consciousness in the reinterpretation of the past. The meanings that result from these three perspectives are given according to the city of Porto Alegre, in the neighborhood Esplanada, when the chacacter tunrs 30, and in the maturity he feels able to establish relationships between childhood, youth the maturity, the which follows the quest of the past that somehow determines the present.
\end{abstract}

Keywords: identity; city, memory, consciousness.

Uma espécie de mapa aberto da sua história, com legendas pra tudo que já tinha sentido e experimentado em trinta anos de vida, um bairro que já tinha sido o cosmos e hoje é uma cidade de brinquedo pela qual transita evocando fantasias antigas. (GALERA, 2006, p. 175)

A identidade (e a indefinição desta) da sociedade contemporânea realiza-se pela fragmentação e pela variedade que a cidade oferece aos indivíduos. Estes, em sua trajetória

\footnotetext{
* Mestranda em Estudos Literários pela UFRGS. Professora municipal de Passo Fundo de Artes, Língua Portuguesa, Literatura Brasileira e Língua Espanhola.
} 
urbana cotidiana, buscam a sua identidade, a qual está em constante construção, posto que inacabada. Isso acontece pela recuperação dos fragmentos do passado, ligado aos lugares da cidade, também em constante transformação.

Entendemos que a cidade se constrói e é construída pelos sujeitos que vivem nela. A história de ambos se entrelaça. Desse modo, a cidade, em sua historicidade, significa na vida e na busca da identidade dos sujeitos e estas fazem sentido na cidade, com sua busca e os discursos que tecem transformações. Os habitantes urbanos têm sua identidade em constante construção e a cidade acompanha este processo. De acordo com Eni Orlandi, a cidade e seu espaço podem ser entendidos como um "projeto em movimento, sobre o qual incidem os movimentos do sujeito e do sentido" e, também, como "espaço material concreto funcionando como sítio de significação que requer gestos de interpretação particulares. Um espaço simbólico trabalhado na/pela história, um espaço de sujeitos e de significantes." (ORLANDI, 2001, p.12).

A busca pela identidade por meio da memória e dos fragmentos do passado, ligados aos lugares da cidade, pelos quais o indivíduo passou - e ainda passa - na trajetória que percorre rumo ao encontro consigo mesmo, os sentidos que os espaços urbanos têm para o personagem/sujeito citadino, são o foco deste trabalho. A análise centra-se na busca do personagem-protagonista Hermano, do romance Mãos de Cavalo, de Daniel Galera, que anda de carro pelas ruas da cidade de Porto Alegre, a princípio com o intuito de buscar seu amigo Renan para uma viagem rumo ao Altiplano Boliviano para escalar uma montanha. Porém, o rumo da viagem se modifica quando ele começa a lembrar de seu passado e isso motiva o retorno ao Bairro em que nasceu. Um acontecimento, entretanto, altera o seu percurso, trata-se que um espancamento que ele vai relacionar à morte de seu amigo no passado.

Isso o leva a rever as ruas de sua infância e a adolescência e algumas pessoas de seu passado, como Naiara, irmã de Bonobo - sua primeira experiência sexual marcante. Está, então, com trinta anos e resolve revisitar os lugares que fazem parte de suas lembranças, todas narradas em fragmentos ou, como está escrito na orelha do romance Mãos de cavalo:

A chave que une os episódios são ritos de passagem típicos da infância e da adolescência, momentos de pura ação que, às vezes num átimo de segundo, determinam a personalidade e o destino de quem os presencia. É o caso do protagonista de Mãos de cavalo, um homem de poucas palavras cujos segredos são narrados em fragmentos. Em sua trajetória rumo ao cotidiano morno do mundo adulto, preenchido entre o sucesso profissional e o "piloto automático" de um casamento fora dos planos, é impossível deixar para trás as marcas ainda latentes desse passado: a morte, as primeiras experiências afetivas, a sexualidade nem sempre imune a turbulências. (GALERA, 2006, orelha) 
Os ritos de passagem de Hermano ligam-se à cidade e a busca pela identidade impulsionam o retorno e a realização de encontros com o passado e com ele mesmo. Denominamos processo como consciência da identidade, que é volátil e mutante e está sempre em transformação. Portanto, cidade e personagem se modificam e é isso que possibilita a integração dele ao mundo, isto é, pertencer a ele. De acordo com Zygmunt Bauman

Tornamo-nos conscientes de que o "pertencimento" e a "identidade" não têm a solidez de uma rocha, não são garantidos para toda a vida, são bastante negociáveis e revogáveis, e de que as decisões que o próprio indivíduo toma, os caminhos que percorre, a maneira como age- e a determinação de se manter firme a tudo isso- são fatores cruciais tanto para o "pertencimento" quanto para a "identidade".(BAUMAN, 2005, p.17)

A identidade do personagem, bem como seu sentimento de "pertencimento" ao bairro Esplanada se transformam, e o narrador em $3^{\mathrm{a}}$. pessoa do romance Mãos de Cavalo mostra essa trajetória mutante e o desenvolvimento dessa identidade e de sua transformação, a partir das decisões de Hermano, o "Mãos de Cavalo" . Algumas dessas decisões são definitivas para sua identidade social e para a entrada para a vida adulta, e essas implicam, também, a questão do "pertencimento" ao local urbano.

A representação da trajetória em busca da identidade que este personagem percorre, em Mãos de Cavalo, assemelha-se ao que Bauman afirma em relação à identidade e ao pertencimento ao local urbano. Pode-se dizer isso, tendo em vista que essas particularidades do protagonista não têm "a solidez de uma rocha" e o desenvolvimento de sua transformação é negociável e revogável pelas mudanças na vida de Hermano. Abordaremos essas questões quando tratarmos da relação entre a sua transformação e o espaço urbano, considerando que o presente funciona como catalisador, e possibilita a resolução de um conflito ocorrido no passado, mas que afeta o presente.

Tudo isso instaura um novo sentimento de "pertencimento" em relação ao bairro e ocorre, sobretudo, pelo distanciamento e pela possibilidade do personagem de rever sua trajetória, a qual, nesse trabalho, será analisada em três níveis: o espacial; o temporal e memória e da consciência, os quais passamos a analisar a seguir.

\section{1 identidade e pertencimento: nível espacial}

No nível espacial, constitui-se o sentimento de identidade e de pertencimento, e o denominamos de nível de distância espacial porque Hermano afasta-se do Bairro Esplanada quando se casa e se torna cirurgião plástico, mudando-se para o centro de Porto Alegre. Trata- 
se, pois, de uma distância geográfica e, ao mesmo tempo, da existência das diferentes facetas de sua identidade, porque os lugares urbanos dizem respeito a momentos da sua vida e correspondem em sua transformação.

A distância geográfica é fundamental para a transformação da identidade de Hermano via consciência, e demonstra a diferença entre o "Mãos de Cavalo" adolescente, ainda em processo, e o personagem amadurecido, cuja visão se transforma pelo afastamento dos locais públicos urbanos, pertencentes ao bairro Esplanada, onde se processou parte do desenvolvimento de sua identidade. A visão do personagem, sob a ótica do narrador em $3^{\mathrm{a}}$. pessoa, mostra a faceta identitária de Hermano criança, adolescente que vê um sentido diferente do bairro em comparação ao Hermano adulto. Para chegar ao nível de consciência, o personagem precisou afastar-se e tornar-se "outro", ou seja, adulto, não mais o adolescente de quinze anos. Assim, através da representação do narrador e pelo olhar ressignifica os locais públicos urbanos, ligados a sua origem.

Essa distância espacial significa pensar como cada local público tem novo sentido para o personagem em cada faceta de sua identidade (facetas ligadas aos ritos de passagem: infância, adolescência, idade adulta). A primeira faceta relaciona-se aos lugares urbanos do bairro ligados à afirmação da masculinidade, importante para a identidade deste adolescente. A segunda se liga à sua nova condição:, tendo em vista que se trata de um homem casado e próspero cirurgião plástico, que se relaciona aos locais urbanos pelos quais passou para se formar e atuar como médico, e depois retorna ao bairro Esplanada com outro olhar. Entre esses lugares há uma distância pertinente, tanto espacial, quanto de sentido. As duas facetas implicam o sentimento de pertencimento, cujas relações sociais contribuem para ressignificar esses locais públicos urbanos na identidade do personagem.

Na obra há a representação do Hermano criança e adolescente, formando sua identidade através desse sentimento de pertencimento que ele possui com o bairro Esplanada. Esse "pertencimento" altera-se pelo seu retorno ao bairro em que o protagonista não mora mais, ele já não é a mesma pessoa, tampouco o bairro permanece igual. Os dois - personagem e cidade - transformam-se, porque há novas relações de sentido com outros lugares da cidade e também com outras pessoas.

As primeiras facetas da identidade do protagonista - criança e adolescente - se constituem na situação de morador do bairro deste personagem, que se sente, ao mesmo tempo, parte do bairro Esplanada e também um pouco estrangeiro, solitário: "De repente, se sentiu muito sozinho. Não tinha intimidade com nenhuma daquelas pessoas.” (2006, p.89). Isso ocorre devido à sua dificuldade de envolver-se de verdade em seus relacionamentos 
sociais, travados nos locais públicos de Esplanada e de toda a significação que eles possuem, para o protagonista e para os demais. Dessa forma, o pertencimento ao bairro se configura de modo ambíguo para o personagem, que está "dentro", mas ao mesmo tempo, sente-se "deslocado", "fora" de seu contexto social. De acordo com Bauman

Estar totalmente ou parcialmente "deslocado" em toda a parte, não estar totalmente em lugar algum (ou seja, sem restrições e embargos, sem que alguns aspectos da pessoa "se sobressaiam e sejam vistos por outras como estranhos), pode ser uma experiência desconfortável, por vezes perturbadora. Sempre há alguma coisa a explicar, desculpar, esconder ou, pelo contrário, corajosamente ostentar, negociar, oferecer e barganhar. Há diferenças a serem atenuadas ou desculpadas ou, pelo contrário, ressaltadas e tornadas mais claras. (BAUMAN,2005, p. 19)

O personagem está inserido no bairro Esplanada, em um primeiro momento, como morador. É "Mãos de Cavalo", o adolescente de quinze anos, cuja vivência no campinho, na escadaria, nas ruas está dentro da perspectiva de suas relações sociais. Estas são permeadas por um certo temor desse personagem de conviver, em uma relação ambígua entre revelar-se e ocultar-se. O primeiro aspecto pode ser entendido nas situações em que ele mostra as suas habilidades com a bicicleta, na escadaria, durante o jogo do Downhill:

Hermano se afastou uns cinquenta metros rua acima, parou, montou na bicicleta e começou a pedalar com toda a força na direção da escadaria. Ao passar pelo Bonobo, olhou bem na cara dele. Agora ele estava prestando atenção. Agora o Bonobo ia ver. Usou o degrau de tijolos para facilitar a subida na calçada e quando se lançou escadaria abaixo já estava em alta velocidade. [...] Sabia que ia cair. E todos iam ver ele cair. Enquanto descia, teve consciência de que era apenas isso que o movia a descer aquela escadaria tantas vezes, a possibilidade da queda, de se arrebentar no chão. E essa seria a mais espetacular de todas. Era o que tinha a dizer às pessoas lá em cima. Estava pronto para sangrar. Era o seu talento. Se o Bonobo tinha sido capaz de bater em vinte ao mesmo tempo, agora ele seria capaz de cortar, quebrar, ralar, escoriar, debulhar, raspar, fraturar, arranhar, perfurar e esmagar seu próprio de um jeito que ninguém jamais esqueceria. (GALERA, 2006, p.91)

Machucar o próprio corpo, mutilar-se, cair de propósito de bicicleta na escadaria, nas ruas do bairro era a forma encontrada por Hermano adolescente de afirmar-se perante os outros, de que podia ser tão ousado, viril e corajoso como julgava ser Bonobo. Esse "mostrarse" é suscitado pelo local e pelos sentidos atribuídos a ele pelo protagonista e demais jovens personagens. Ao mesmo tempo, o "ocultar-se" quer dizer afastar-se, não criar laços, não se comprometer e, principalmente, não falar de si. É nesse ponto que entra a dialética entre os locais públicos e as relações sociais inerentes a eles. Eni Orlandi afirma que: "Relações sociais são relações de sentido e estas estão, nessas condições, preenchidas pela sobredeterminação do urbano. Não restam espaços vazios na cidade, sua realidade estando toda ela preenchida pelo imaginário urbano." (ORLANDI, 2001, p.14).

Os lugares urbanos estão atrelados às relações sociais, que os significam. Por isso que não existem espaços vazios. Para o personagem Hermano, de "Mãos de Cavalo", cada lugar 
urbano é ligado a uma parte de seu passado ou presente, revisitados pela memória, com suas relações sociais específicas, que só fazem sentido quando ligadas a este determinado lugar urbano. É o caso dos personagens Bonobo, Naiara e Morsa, cujo sentido só existe relacionado ao Bairro Esplanada, fora dali não há mais significação, do mesmo modo procede com a esposa Adri e o amigo Renan, entendidos em outros contextos e lugares urbanos da cidade de Porto Alegre

Os locais urbanos são entendidos na obra por essas relações sociais, que se configuram, no entanto, problemáticas para o protagonista, uma vez que ele não se envolve de verdade nelas. Se, de um lado, ele se automutila na esperança de se comunicar, de "sentir-se parte do grupo e do bairro", por outro lado, demonstra, por vezes, não querer que falem dele, que o observem e o avaliem

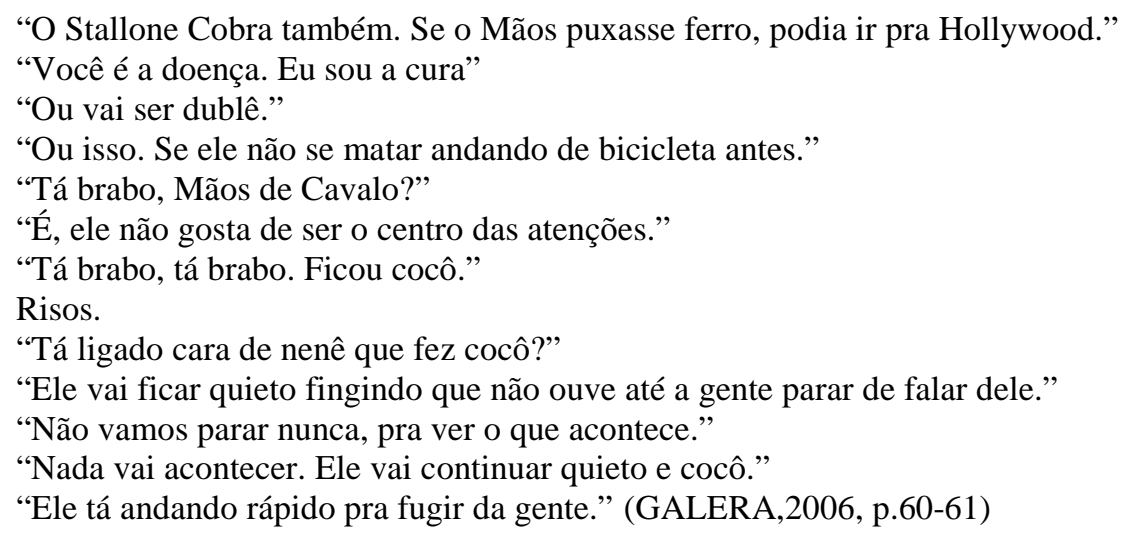

O protagonista do romance passa essa dialética do sentimento de pertencimento com o bairro Esplanada, no sentido do "revelar-se" e do "ocultar-se", nessa perspectiva dúbia entre o "estar dentro" e "estar fora" do local urbano e seu contexto social, explicitada por Bauman (2005), do esconder e, ao mesmo tempo, corajosamente ostentar. Essa perspectiva se caracteriza na ação do personagem de ostentar-se, ferindo seu corpo e esconder-se, fugindo das avaliações de seus companheiros, vizinhos, evitando mostrar seu interior e suas ideias.

O personagem principal tem dificuldade para se relacionar. Apesar disso, três personagens - Bonobo, Morsa e Naiara - são significativos para a formação da identidade do protagonista. Essa importância se estabelece pelas relações sociais que ele tem com eles dentro dos espaços públicos do Bairro Esplanada. Quer dizer que os personagens se constituem como sujeitos que atuam, significam e ressignificam esses locais de convivência, e esses sentidos repercutem-se na identidade do protagonista Hermano, que também atribui sentidos aos espaços urbanos públicos, conhece-se por eles e pelas relações sociais que trava, principalmente, com eles, pelo que são dentro desse espaço localizado de Esplanada. 
Na dialética do "estar dentro e fora" do bairro, o protagonista sente-se pertencente à Esplanada, na medida em que este local se caracteriza como o lugar de suas vivências, da passagem de seus ritos, e seus recantos (campinho, escadaria, morro da Polícia) são significados por ele e pelos outros habitantes com os quais se relaciona. Os personagens Bonobo, Morsa e Naiara estão inseridos em uma perspectiva de pertencimento dialético, em que se sentem "dentro" e "fora" desse bairro. Sob essa perspectiva, no sentido de estar "dentro", é como os demais habitantes desse bairro se sentem, de acordo com a narrativa. Embora o local que habitam seja um loteamento, com lugares que, a princípio, parecem estar sem harmonia, os moradores o consideram um bairro e se sentem parte dele:

Para chegar ao Morro, antes era preciso atravessar o mato, um bosque abundante de cipós (...) À direita de Hermano, em aclive formado por uma sequência de longos e suaves degraus no terreno, se estendia o restante da praça, com parquinho infantil, quadra de bocha, uma churrasqueira coberta e alguns bancos de cimento. Na percepção de Hermano, não havia harmonia entre todos esses elementos. Não pareciam fazer parte de um mesmo ambiente, no caso a praça principal de Esplanada, que era o nome de um loteamento residencial mas operava na psicologia de seus moradores como algo muito mais imponente, como o nome de um verdadeiro bairro. Se a Esplanada ainda não era um bairro, um dia seria. $\mathrm{O}$ fim de tarde no campinho era como um cenário de um sonho, que se monta sem muita preocupação com a realidade da qual deriva. (GALERA,2006, p.60)

O personagem Hermano experimenta a sensação do pertencimento ao bairro ao se relacionar especialmente com alguns de seus locais, atrelados às suas relações sociais, principalmente com Bonobo, Morsa e Naiara: o campinho de futebol, a rua, a escadaria, o Morro da Polícia. Eles fazem parte dos seus ritos de passagem tais como a infância e a adolescência, que fazem retornar a força, a masculinidade e a aventura

Hermano não gostava muito de jogar futebol. Era um zagueiro medíocre que uma ou duas
vezes por ano, no máximo, por pura sorte, conseguia fazer um gol, dando um chutão do fundo
da quadra. Suas motivações para participar dos jogos eram imprecisas até para ele mesmo. O
esforço físico lhe agradava. Ser eventualmente observado pelas gurias era outro estímulo
inegável. O que atraía não era o jogo, a competição ou mesmo a interação com os amigos do
bairro, mas antes o ambiente, o cenário, a oportunidade de estar imerso na atmosfera que
envolvia o campinho nos finais de tarde. (GALERA,2006, p.60)

O futebol era a forma de provar sua masculinidade e de fazer parte do grupo. E o ambiente que proporcionava isso, que trazia toda essa carga de sentido era o campinho do bairro, que consiste em um dos locais urbanos, dentro do bairro, que faz sentido para Hermano e suas relações sociais estabelecidas nesse lugar.

Essas relações sociais são o ponto chave para entender porque "Mãos de Cavalo" também se sente estrangeiro em seu próprio bairro. Ele se relaciona com os demais habitantes, mas de uma maneira superficial, sem se envolver de verdade com ninguém. Essa dificuldade de relacionamento se torna visível pela preocupação do personagem com a imagem que os 
outros fazem dele e da sua relação com cada local público do bairro. Um exemplo é o campinho de futebol, pois para ele é muito importante ser observado pelas meninas e seus companheiros de jogo e com o que ele pode fazer ou não neste lugar. Na perspectiva das relações sociais imbricadas no local urbano, uma das mais importantes é o personagem Bonobo

Havia, porém, algo mais. Algo que vinha correndo em sua direção como se buscasse uma
trombada proposital. Algo que olhava nos seus olhos e sorria um sorriso de intimidação. Algo
a que Hermano só se expunha tão abertamente naqueles jogos de bola, onde os diferentes
níveis de agressividade inerentes ao temperamento de cada jogador eram ajustados, pela
própria natureza do jogo, ao redor de um denominador comum. Nas partidas de futebol do
campinho, Hermano podia, até certo ponto, se aproximar de Bonobo. Podia olhar ele de perto,
observar seu andar semiereto e suas feições símias. Podia dar um carrinho no Bonobo. Na
posição de zagueiro, era o que se esperava dele. Impedir, a qualquer custo, que qualquer
atacante, Bonobo ou não Bonobo, chegasse perto do gol com a bola no pé. (GALERA,2006,
p.61)

O campinho significava igualdade de condições entre Hermano e Bonobo, este último considerado mais forte, ousado, corajoso. É no campinho, jogando futebol, que Hermano podia encarar Bonobo, e não em outro lugar.

Hermano espelha-se em Bonobo, quer ser como ele, ao mesmo tempo que o teme. $\mathrm{O}$ campinho, cuja atividade importante se configura no futebol, é o lugar em que pode chegar perto dele, porque a posição de zagueiro lhe propicia isto, ao contrário de outros locais do Bairro Esplanada. Através dessa posição, marca Bonobo e se choca a seu corpo. Este o ameaça de surra. A violência e o imaginário como componentes formadores de masculinidade se configura como central para Hermano. Embora se chocando contra Bonobo no campinho, evita o embate corpo a corpo com ele. O simples fato de olhar se configura como a aceitação do desafio.

O campinho se constitui na dialética entre repulsa e atração que Hermano tem em relação à violência como formadora da identidade masculina. O futebol se caracteriza como embate físico. O modelo está em Bonobo. Já Morsa, ao contrário de Bonobo, caracteriza-se como um elemento de segregação, de não adequação ao comportamento e aparência vigentes adotados nesse local pelos outros meninos. Eles consideram que Morsa não sabe jogar futebol. Se Morsa é segregado, embora procure integrar-se, estando presente nos eventos sociais do grupo, Naiara, como presença feminina, é passiva: ela não participa das atividades realizadas no campinho. Apenas observa, e sua opinião é desconsiderada. De um lado, podemos constatar isso no momento em que ela tenta intervir no eminente confronto entre Hermano e seu irmão. Naiara diz: "Mano, deixa ele. Foi sem querer, ele não sabe jogar direito". E Bonobo responde: "Não te mete, guria”, GALERA (2006, p.38). Por outro lado, se 
a sua opinião sobre os eventos sociais é desconsiderada, no campo da sexualidade, como menina, possui mais poder de decisão. As meninas se configuram, nesse espaço, conforme o narrador “[...] gurias que observavam o jogo e ridicularizavam aos berros os mesmos guris que mais tarde, de bruços na cama, elas transformavam em protagonistas de suas desde sempre elaboradas fantasias sexuais [...]" (GALERA, 2006, p.31).

Outro espaço que significa afirmação de masculinidade para Hermano é o Morro da Polícia. No bairro, este local é onde se encontra a base do exército. A ideia de exército liga-se ao imaginário da violência, da força, e é relacionada a Hermano, especialmente, ao seu apelido de adolescência, "Mãos de Cavalo". Nesse momento, Bonobo e Morsa não estão presentes. Isso significa que estão também "fora". Naiara, ao contrário, está presente e é um espaço em que pode interagir mais com sua opinião, ao contrário do futebol e do Downhill. Ela tece comentários e questiona Hermano sobre a questão dele servir no exército ou não. Naiara ressignifica Hermano dentro do espaço Morro da Polícia, que remete à ideia do exército. Associa as mãos de Hermano com a força necessária para servir no exército:

“E tu, Mãos?" Naiara ia saltando de uma pedra a outra, tentando percorrer o caminho sem pisar na terra.

"O quê."

Hermano nunca tinha pensado no assunto. Na verdade, não entendia muito bem do que os outros estavam falando. O próprio conceito de exército era meio insólito para ele.

"Não sei. Falta tempo ainda."

"Tu devia servir, Mãos. Braço forte, mão amiga.” (GALERA,2006, p.60)

Os amigos de Hermano, especialmente Naiara, têm um determinado imaginário em relação a ele. Suas mãos grandes remetem a ideias como força, masculinidade e vigor. O morro da Polícia é um local urbano do Bairro Esplanada que se constitui pela carga significativa que o exército têm, na questão desses atributos e ainda à fantasia do heroísmo.

Esse heroísmo o protagonista busca desde a infância, quando andava de bicicleta. A ousadia e o heroísmo associados à bicicleta aparecem representados pela escadaria e pelas ruas do bairro. Na escadaria, ocorrem os campeonatos de Downhill. Este espaço significa desafio, ousadia, coragem para dar saltos com a bicicleta da forma mais perigosa e espetacular possível. A regra desse jogo era cair de uma forma que impressionasse os outros competidores. Nesse lugar, a presença de Bonobo é definidora e significativa. Ele domina este espaço, de modo que Hermano tem dificuldade de conviver com os outros que atuam nesse lugar. Morsa também não está presente, o que reafirma sua condição de isolamento no bairro. Naiara tem aqui, também, uma presença pouco significativa em suas opiniões, mas significativa no plano sexual, conforme sinalizamos anteriormente. 
Este espaço público se constitui, assim como o campinho de futebol, fundamental para Hermano, uma vez que é a forma que encontra de se expor, no que ele considera como o seu melhor, que é fazer saltos espetaculares com a bicicleta. O narrador explicita que "Hermano saltou sobre a lombada. Lá no topo da escadaria, alguém honrou a manobra com um grito empolgado. Era bom naquilo. Era o melhor. Quase sempre ganhava. E levava os tombos mais espetaculares." (GALERA, 2006, p.89).

Essa era a forma que o personagem encontrou de comunicar, por meio dos sentidos desse lugar público, um pouco de si e afirmar, para si mesmo e para os outros, que podia realizar sua fantasia de ser "um herói”, de legitimar o imaginário adolescente da masculinidade. $\mathrm{O}$ mesmo referencial ele tem quando criança, ao andar de bicicleta, aos dez anos de idade, nas ruas de Esplanada. Nesse momento, ele encarna uma nova identidade imaginária: a do ciclista urbano.

O ciclista urbano é uma espécie de misto de herói com atleta que enfrenta todos os obstáculos que a cidade oferece. Nesse momento, o menino Hermano se sente um herói, semelhantemente como quando, adolescente, desce a escadaria, durante o campeonato de Downhill. Na sua imaginação, ele não é mais o menino, é o ciclista urbano que enfrenta as ruas hostis da cidade

Mesmo compenetrado, o Ciclista Urbano saboreia seu segredo, a calçada das ruas residenciais das grandes cidades. Ninguém mais reconhece as calçadas como o terreno definitivo para o exercício do ciclismo radical de alto nível e periculosidade. (GALERA, 2006, p. 15)

Retorna o sentimento do temor e do perigo que a cidade pode proporcionar aos seus moradores. No caso do menino, as ruas representam a sensação de adrenalina que ele tem ao transitar por elas, perigosamente, com a bicicleta. Por isso, essas ruas se constituem como perigosas, por causa dos obstáculos das calcadas, do trafego de carros, entre outros. De acordo com Bauman (2005, p. 55), o ambiente da cidade é perigoso para seus habitantes por uma série de fatores: a insegurança pessoal em relação à criminalidade ao trânsito. No caso deste ultimo, as ruas são perigosas pelo fluxo de pessoas e veículos que há, de modo que os carros são caracterizados como: “Tais veículos parecem mitigar o medo que as classes medias urbanas sentem quando se deslocam dentro de 'sua' cidade ou quando ficam paradas no trânsito." (GALERA,2006, p.173). Essa fantasia aparentemente se desfaz com a morte de Bonobo, e mais tarde diz que

Bonobo [...] já sem respiração, com aquela ausência de vibração orgânica que só podia significar que estava sem vida, era a morte, e uma morte da qual Hermano sentiu-se imediatamente cúmplice devido a uma covardia que finalmente se mostrava inteira e que ele estava convencido a manter em segredo, pois não suportaria continuar vivendo se precisasse ostentar essa covardia dali para a frente como uma cicatriz na testa, ser o cagalhão, aquele que 
entrou no mato e ficou quietinho enquanto batiam tanto no seu amigo que o acabaram matando, não, isso seria insuportável, e a solução encontrada no momento veio na forma de um soco, não uma figura de expressão e sim um soco, não uma figura de expressão e sim um soco literal que Hermano deu nele mesmo, no próprio rosto [...] (GALERA,2006, p.173)

Esse fato motiva a transformação de Hermano, que julga não ser mais possível realizar a sua fantasia de heroísmo, porque se sente culpado por não defender Bonobo das agressões da gangue de Uruguaio. Por isso, desiste, momentaneamente, da fantasia, e inicia a construção de sua outra faceta, a de cirurgião plástico.

O desenvolvimento dessa nova faceta da identidade leva-o a relacionar-se com outros lugares urbanos e o encaminha, consequentemente, ao abandono das relações sociais e dos locais públicos que lembram o heroísmo e a afirmação da masculinidade. Daí a importância da distância espacial, neste momento. À medida que se afasta do campinho, da escadaria, do Morro da Polícia e dos amigos se instaura a mudança. Hermano busca lugares da cidade que remetem à ideia de esforço, disciplina, estudo e profissionalismo, dentre esses, o cursinho pré-vestibular, a UFRGS e os hospitais. A morte de Bonobo desencadeia o rito de passagem da adolescência para a idade adulta e ao afastamento gradativo do bairro. Com isso, passa a viver no centro da cidade e a estabelecer novas relações de amizade.

O primeiro momento - o do afastamento das relações sociais e, dos locais antes importantes - ocorre logo após o enterro de Bonobo. Hermano decide se transformar, e isso sinaliza a lógica da distância espacial entre ele e o bairro, e, também, com os locais públicos urbanos antes frequentados

Tudo o que fez desde aquele domingo em 1991 [...] digerindo a experiência de sua primeira visita a um cemitério, o primeiro enterro, construindo um abrigo em meio a uma tempestade mental, planejando como seria a sua vida dali pra frente como se planejasse sua transformação lenta e obstinada em um super-herói que ressurgiria quinze anos depois pra ser admirado por seu autocontrole e inteligência. [...] Quinze anos atrás, decidiu que permaneceria trancado em casa lendo e estudando ate esgotar a capacidade de concentração, saindo apenas pra esgotar o corpo em pedaladas de sessenta quilômetros até o Lami ou corridas de uma hora de duração pelo calçadão de Ipanema, numa rotina tão solitária quanto possível, absolutamente focada na superação de seus próprios limites e na manutenção de um nível de exigência pessoal absurdo, do tipo que poucos seres humanos teriam a capacidade de cumprir. Foi pesquisar qual era ao curso superior mais difícil da universidade mais exigente do estado e a trilha o conduziu ao ofício que lhe parecia claramente destinado, a profissão que justificaria uma entrega completa à disciplina e ao mesmo tempo absorveria seu fascínio pelo sangue, pela mutilação, um sentimento ambíguo que combinava a atração estética pela violência a um medo francamente covarde da violência de fato. Aprenderia a domar seu impulso, a domesticar o sangue, a aplicar a violência de forma científica com a nobre finalidade de curar outros seres humanos. Decidiu como seria o resto de sua vida inteira na semana que se seguiu ao funeral. Se tornaria um médico. O melhor médico. (GALERA, 2006, p.126)

O processo de construção dessa nova identidade, que perpassa a passagem da adolescência para a idade adulta, exige a distância gradativa do bairro Esplanada. Durante essa trajetória, o personagem se desliga aos poucos do bairro e suas relações sociais e entra 
em contato com outros locais da cidade. O narrador sinaliza que Hermano "se afastou quase completamente dos amigos da Esplanada, que por um tempo ainda vieram a sua procura com acusações de 'sumido', 'azeite” e 'escamoteado', mas depois de algumas semanas o largaram de mão." (GALERA, 2006, p.127).

A escola, primeiramente, é o lugar antes negligenciado perante os outros, como o campinho de futebol, as ruas, a escadaria e o Morro da Polícia. "No segundo semestre daquele ano, completou a segunda série do segundo grau com notas acima de 9,2, e durante todo o ano seguinte não teve nenhuma nota abaixo de nove." (GALERA, 2006, p.127). Em seguida, Hermano vai para o Cursinho Pré-vestibular e o frequenta durante quatro meses. Mudou o modo de vier, passando a ler jornais e a interessar-se por disciplinas acadêmicas.

Após o cursinho, o vestibular. Passou em primeiro lugar na Federal do Rio Grande do Sul e concluiu a graduação com o mesmo afinco, realizou mais dois anos de residência médica em cirurgia geral e mais dois em plástica no Hospital Ernesto Dornelles. Depois abriu o seu consultório, quando já estava com vinte e oito anos de idade. Nesse período continuou morando em Espanada, mas se afastou dos lugares que foram importantes na infância e na adolescência, abandonando também as relações pessoais e de amizade.

Diante desses afastamentos e abandonos, o sentimento de pertencimento mudou, pois Hermano já não se sentia apenas parte do Bairro Esplanada, mas da cidade Porto Alegre. O bairro deixou de ser o único referencial da cidade significativo para sua identidade. A escola, o cursinho Pré-vestibular, a UFRGS, o Hospital Ernesto Dornelles mudaram os sentidos de identidade para o protagonista e são responsáveis por uma nova faceta identitária que se acrescenta à forma como se vê atuando na cidade. Decorre disso, a distância geográfica e a negociação de transformação do personagem no que diz respeito ao que Bauman (2005) afirmou sobre as ideias de "pertencimento" e de "identidade" no que tange aos espaços urbanos.

Durante esse processo, o personagem ainda é morador do bairro Esplanada, mas o sentido de "pertencimento" é outro, diferenciando daquele de antes da morte de Bonobo. O personagem se sente "fora" do bairro, até desligar-se completamente. Nesse tempo em que estudou para ser médico, há menção apenas aos lugares urbanos e não às relações sociais que o personagem havia estabelecido, até porque ele se isolou completamente para alcançar seus objetivos acadêmicos. No final da graduação, contudo, Adriana entra em sua vida e instaura questionamentos em relação à vida de solteiro, que era uma escolha e uma intenção, pois não via como um possível casamento poderia melhorar a sua vida. As namoradas não haviam significado muito para ele, ao contrário, tomavam o seu tempo, mas com Adriana foi 
diferente, "não era a primeira vez que ficava com uma mulher, mas era a primeira vez que estava com uma mulher, e ela tinha a mesma idade, estudava Artes Plásticas [...] e dizia em dúbio tom de brincadeira que precisava de um homem que fosse se tornar um médico [...]" (GALERA, 2006, p.51). Ele a via como inconveniente, porque dizia que queria casar com um médico rico para sustentar seus caprichos. Mas enfim, ela era bonita, apesar de inconveniente e encantadora.

A sua dificuldade de se relacionar novamente aparece a partir da relação com Adriana, mas ele sente que, pela primeira vez, estava se envolvendo de verdade, e não era da forma como ocorreu com outras mulheres. Nem mesmo com Naiara, que foi sua primeira experiência erótica importante e marcante. A relação com ela se efetiva institucionalmente por meio do casamento. Ele rompe, então, com o sentimento mais forte de pertencimento ao Bairro Esplanada - o de morador. Afasta-se geograficamente e passa a residir mais próximo do centro, instaurando relação com outros lugares da cidade de Porto Alegre.

Cerca de um ano depois, semanas após a sua graduação, estavam casados, morando num antigo apartamento de um quarto de propriedade da mãe dela, numa quadra nobre do bairro Petrópolis. E a verdade é que seu objetivo de estender a felicidade daquelas horas da madrugada na Praia do Lami pelo maior tempo possível pode ser considerado o maior fracasso de sua trajetória, pois nada parecido com aquilo jamais voltou a ocorrer. Sua vida juntos parecia ter passado de maneira rápida e automática. (GALERA, 2006, p.52)

Hermano e Adriana residem no Bairro Petrópolis, área privilegiada de Porto Alegre e com sentidos opostos ao Bairro Esplanada. Isso tem a ver com a posição social. O bairro é "nobre" e condiz com a nova faceta identitária, e também com relacionamento com Adriana. Ele é um cirurgião plástico e ela uma artista plástica e o contexto é, além de distante geograficamente de Esplanada, também oposto a ela, no que tange às relações sociais e de identidade. O autoconhecimento de Hermano se constrói pelos dois lugares: o bairro Esplanada e o bairro Petrópolis.

Esse novo contexto, no entanto, revela-se insuficiente para o personagem conseguir empreender a busca por si mesmo. A princípio, o casamento o decepciona. Sente que vive esta relação de forma "automática". E esse fator é um dos motivadores para a busca de sua identidade e perpassa pelo seu breve retorno ao Bairro Esplanada, aos trinta anos de idade. Essa busca forma-se não só pelo nível da distância geográfica, como vimos, mas também pelo nível temporal, da memória e, como nível mais profundo e definidor dessa busca, o da consciência, que ocorre efetivamente no momento do retorno. 


\section{Transformação da personagem: distância temporal e memória}

O nível de distância temporal consiste na passagem do tempo e considera as transformações da personagem que envelhece e assim como o bairro Esplanada também muda e passa pelos menos processos. O protagonista adulto, de trinta anos, não vê o bairro da mesma forma como antes, quando era um menino de dez e um adolescente de quinze anos. Esse nível de distância do olhar, do sentimento de "pertencimento" ao local é tão importante na busca da identidade quanto o da distância geográfica. O sentimento de pertencimento mudou e o protagonista adulto se sente ligado ao bairro por relações identitárias relacionada aos ritos de passagem, mas percebe que sua identidade transcende às significações do bairro Esplanada. Ele faz parte da cidade de Porto Alegre e do mundo. Seus horizontes se expandem e isso se constata na forma como o personagem vê o loteamento com o passar dos anos, mediado pelo seu processo de amadurecimento e envelhecimento.

$\mathrm{Na}$ sua infância, o bairro era visto de uma forma e quando adulto a via de outro modo. Acompanhara as mudanças - "Tinha acompanhado a crescente ocupação daquele sul desde nascimento até a vida universitária, presenciando a transformação gradual da paisagem à sua volta. Lembrava bem da época em que aquele terreno era um loteamento quase virgem, cada terreno baldio guardando um segredo [...]" (GALERA, 2006, p.123). A mudança do loteamento segue a urbanização progressiva da cidade. Se na infância de Hermano o espaço é semi-rural, na idade adulta o bairro se modificou com o passar do tempo e do progresso urbano.

\footnotetext{
Ao retornar agora, anos depois de ter se mudado pro apartamento da mãe de Adri em Petrópolis e, recentemente, pra casa de três quartos na Bela Vista, a vocação residencial de Esplanada lhe salta aos olhos com uma profusão de loteamentos fechados, condomínios horizontais e um novo supermercado. Ruas de pedras e terra batida estão asfaltadas. A arquitetura predominante nas centenas de residências erguidas nos últimos anos lembra um grande subúrbio de moradias padronizadas. (GALERA, 2006, p.123)
}

A mudança do bairro Esplanada representa, na ficção, para o personagem Hermano, o medo da urbanização da cidade com sua crescente modificação, dentre elas o aumento da população, que instaura o sentimento de insegurança, em relação, sobretudo, a estranhos que invadem as residências. Isso explica o surgimento dos condomínios fechados, citados na obra como uma das mudanças que o narrador em terceira pessoa expõe, indiretamente, pelo olhar do personagem Hermano.

Bauman, no que tange aos condomínios diz que "[...] trata-se de um lugar isolado que fisicamente se situa dentro da cidade, mas, social e idealmente, está fora dela. Presume-se que as comunidades fechadas sejam mundos separados", (BAUMAN, 2009, p.39). Segundo o 
mesmo autor, as mensagens publicitárias são responsáveis por esse efeito, à medida que prometem vida plena e qualidade de vida. "Uma das características mais relevantes dos condomínios é o seu isolamento e sua distância da cidade.... Isolamento quer dizer separação de todos os que são considerados socialmente inferiores", (idem). O ponto chave desses condomínios é a segurança e a sensação de estar sendo vigiado.

No romance Mãos de Cavalo, a mudança do bairro Esplanada é mudança gradativa e relaciona-se ao tempo na dinâmica urbana das cidades. O protagonista Hermano percebe que a insegurança, refletida nos condomínios de Esplanada, se constitui desencadeia um novo sentimento de temor pela cidade. O protagonista se depara, também, com sua antiga casa modificada e questiona o rumo que sua vida tomou. A venda da casa antiga "teve muito mais a ver com a antecipação de seu próprio futuro do que com o interesse de seus pais. Ao se dar conta disso e ver o que os veterinários fizeram com a casa, se sente um lixo. Não tem mais certeza se tudo aquilo era necessário." (GALERA, 2006, p.125).

O personagem se sente culpado pelas modificações ocorridas na casa e credita isso à sua decisão de se transformar e de afastar-se definitivamente do bairro. Esse sentimento se configura na forma representada pelo modo como o personagem, em seu retorno, vê o bairro, mediado pela distância temporal. Nesse sentido, é importante que se ligue os contextos urbanos e os sentidos ao mesmo tempo semelhantes e diferentes em relação à representação da identidade e à memória, como o que ressoa, estabelecendo retornos de tempos já vividos, mas sempre latentes no presente, como que o que ficou sem resolução em outro tempo mais distante. A memória se constitui, nesse romance, como a rememoração da história, como o que sustenta os conflitos e a exigência de resolução de conflitos que ficaram em suspenso no passado. De acordo com Montenegro:

[...] enquanto a memória é múltipla, a história "é uma e podemos dizer que não há senão uma história"; por outro, a memória trabalha e constrói uma representação dos fatos distantes, ou mesmo onde ou quando se encerra a possibilidade de encontrar testemunhas para aquela lembrança. [...] o vivido que guardamos em nossas lembranças e que circunscreve ou funda o campo da memória se distingue da história. Entretanto, se são distintos, arriscaríamos afirmar também que são inseparáveis. Afinal, compreendemos a história como uma construção que, ao resgatar o passado (campo também da memória), aponta para formas de explicação do presente e projeta o futuro. Este operar, próprio do fazer histórico na sociedade, encontraria em cada indivíduo um processo interior semelhante (passado, presente e futuro) através da memória. (MONTENEGRO, 2007, p.17)

Pela memória Hermano recupera os fragmentos de seu passado, que se liga às transformações do bairro. O vivido por Hermano faz parte da história de Esplanada e pelo trabalho da memória realiza-se, pelo viés da personagem, uma versão do que seria da ordem da história e instaura a diferença toda a vez que pela memória retornam sentidos do passado, 
enquanto fragmentos da ordem do vivido. Neste romance, a forma como fragmentos do passado referentes ao bairro retornam e são representados instaura efeitos mais globalizantes da memória que, sendo múltipla, adquire novos significados cada vez que o personagem a revisita.

A representação da busca do personagem por sua identidade, por meio da cidade, pode ser percebida pela ação desse narrador. A organização estrutural do romance, principalmente na forma de sua trama, mostra essa memória. Dentro desta, o narrador entrelaça o presente do personagem, isto é, a sua trajetória de carro pelas ruas da cidade e a memória fragmentária de seu passado, ligando os lugares urbanos, os acontecimentos que marcaram seus três ritos de passagem: infância, adolescência e idade adulta e as relações afetivas pertencentes a esse passado, atreladas aos lugares.

A memória em relação ao personagem organiza-se pela trama que o narrador em terceira pessoa organiza. Essa memória é posta em fragmentos, que estruturam os capítulos (O ciclista urbano, O Bonobo, O morro, Downhill, A festa de quinze da Isabela, Naiara, A clareira e $\mathrm{O}$ enterro) e aparecem dispostos entre capítulos do presente do protagonista, nomeados através das horas que passam desde que saiu de casa até quando vai à casa de Naiara e se despede dela e do bairro.

Os capítulos que configuram o presente de Hermano tratam da decisão do protagonista de abandonar a excursão que faria com Renan para o Altiplano Boliviano para retornar ao bairro de origem, na busca por si mesmo. Eles vêm precedidos na organização do texto, imediatamente, de um fragmento de memória. Isso significa que, tanto no passado, quanto no presente, os fantasmas do protagonista - a fantasia do heroísmo, a relação contraditória com a violência (atração e medo) e a dificuldade de relacionamento - estão presentes. Esses fantasmas estão representados pelo espaço urbano. Nessa perspectiva, o abandono da escalada pode ser explicada pelo seu não sentido dentro da perspectiva de pertencimento e identidade: voltar ao bairro e confrontar os próprios fantasmas, revisitados pela memória, era considerada uma aventura muito maior: o autoconhecimento, proporcionado pelo nível da consciência.

\section{Retorno ao bairro: nível da consciência}

A ideia de pertencimento ao bairro, no entanto, não é suficiente nem absoluta para a questão da identidade. Esta pode transformar-se conforme os anseios e os rumos que o indivíduo toma na vida. Hermano mudou de rumo, de caminho e também de locais urbanos de Porto Alegre, a partir da morte de Bonobo. O Hermano adulto, todavia, retornará ao Bairro 
para resgatar seu "eu" perdido, este interior atrelado às memórias e aos espaços urbanos de Esplanada. No encontro consigo mesmo efetiva-se a consciência e se presentificam fragmentos de suas memórias, bem como os lugares da cidade atrelados e fundamentais na busca de sua identidade.

Esses lugares suscitam o retorno do passado pela memória e representam em relação ao personagem seus três ritos de passagem: infância, adolescência e idade adulta. A partir do momento em ele muda de rumo, sua identidade se transforma e ele passa a frequentar outros lugares da cidade de Porto Alegre. Esses lugares são coerentes com a sua nova condição identitária , estruturando a oposição entre o Hermano do Bairro Esplanada e as ligações com o universo do Hermano adulto e incluem o seu percurso acadêmicos e os espaços que os constituem. Assim, o "pertencimento" e a "identidade" com as ruas do Bairro Esplanada se modificam e se rompem aos poucos, a partir do funeral do personagem Bonobo. Os caminhos de Hermano se modificaram e as suas decisões também seguem o mesmo rumo. A perspectiva do narrador apresenta a visão do protagonista, esses locais aparecem representados de forma panorâmica, pois "continua tudo ali, o campinho de futebol, o "camarote" onde as gurias ficavam sentadas vendo o jogo dos guris, o gira-gira, o trepa-trepa e outros brinquedos do parquinho [...]” (GALERA, 2006, p 131). Mas tudo isso estava diferente, descolorido e parecia "uma maquete 1:20 da praça reproduzida em sua memória".

O processo de consciência só se torna possível porque há um narrador em terceira pessoa que enxerga o personagem inserido neste contexto. Assim, pode-se ver a diferença entre a representação do Hermano jovem e do Hermano adulto. Só este último, pela distância espacial, temporal e da memória consegue chegar ao nível da consciência. A panorâmica de cima dos locais urbanos mostra essa distância e permite ver melhor os acontecimentos vividos nesse espaço. A representação da perda de tamanho dos lugares e objetos indicam sentidos em relação ao passado e a transformação dos locais. Eles não são mais percebidos pelo personagem da mesma forma, e por isso já não têm a mesma importância. Isso indica o abandono da fantasia do heroísmo, cujo espelhamento está nesses lugares da cidade e se personificam em Bonobo.

A consciência sobre o "vivido" em relação a esta fantasia resulta na conclusão, que ao revisitar suas memórias e considerar que apesar de ter se passado muito tempo, o desejo de ser como Bonobo ainda estava presente. O amigo era o seu contrário, mesmo assim o admirava e essa admiração sustentava a convivência de mundos distintos. Buscava Bonobo para satisfazer seus desejos pessoais, querendo ser ele mesmo e funcionou em um espaço curto de tempo, não para sempre. O rompimento desse acordo feito entre o próprio 
personagem mudou o rumo da história. Deu-se com a tragédia que impôs a verdade, ou seja, ele "jamais seria alguém além dele mesmo, e que insistir ser outro era desperdiçar energia e gerar frustração, vergonha e arrependimento [...]" (GALERA, 2006, p.176). O que ficou foi a culpa de não ter defendido o amigo e evitado a sua morte.

O personagem olha para aqueles lugares de Esplanada, em que a fantasia do heroísmo se materializava, e percebe que esta era uma fuga de si mesmo, que seu interior não tinha a ver com aquilo. Através da consciência, aceita sua forma de ser e não tenta mais ser como Bonobo. Dessa forma, conclui que "viver, todavia, não tinha nada de heróico. Aos trinta anos, lhe parecia antes de tudo um constante ensaio pra um heroísmo que nunca chega [...] habitado por projeções fantasmagóricas de si mesmo pelo que gostaria de ter sido no passado ou de ser no futuro" (GALERA, 2006, p.177).

No momento em que a busca parece ter chegado a um determinado ponto e ele percebe de outra forma o seu bairro. $\mathrm{O}$ sentimento de pertencimento liga-se à perspectiva histórica em que o bairro se configura como "uma espécie de mapa aberto da sua história, com legendas pra tudo que já tinha sentido e experimentado em trinta anos de vida, um bairro que já tinha sido o cosmos e hoje é uma cidade de brinquedo pela qual transita evocando fantasias antigas.” (GALERA, 2006, p.175). Relembra, então, a velha escadaria, o andar de bicicleta, as reformas desse lugar e o modo como ele era. Trata-se de uma reavaliação do espaço e de sua vida.

\section{Considerações finais}

A tomada de consciência se efetiva no momento em que o personagem retorna ao bairro para empreender a busca por sua identidade. Isso acontece com o abandono da viagem de escalada com Renan de última hora. Assim, perambula pelas ruas da cidade de Porto Alegre, até chegar às ruas de seu bairro de infância e da adolescência e enfrentar seu medo: a violência, a qual está presente na dialética heroísmo/covardia.

O heroísmo se configura pela tentativa incessante, nas três fases da vida, de superar os seus limites físicos e psicológicos na busca por si mesmo. A covardia deve-se ao fato de o protagonista sentir que não havia dado tudo de si e pela culpa de ter deixado Bonobo morrer nas mãos da gangue de Uruguaio. A relação heroísmo e covardia perpassa a questão da violência e do sangue, e perpassam , também, toda a trajetória do personagem, através de suas memórias fragmentadas, cujas ruas da cidade de Porto Alegre e seus obstáculos urbanos tráfego, calçadas, carros - motivam a sensação dupla de heroísmo/covardia. Primeiro, na 
infância, em que desafiava o trânsito e os obstáculos com a bicicleta, depois, essa necessidade de desafio a si mesmo é substituído pela escalada, porém, em outras cidades.

A cidade de Porto Alegre e seus locais urbanos, como o Bairro Esplanada, por exemplo, oferecem perigos e desafios. Para Hermano, o Bairro Esplanada torna-se hostil, porque o convoca a enfrentar seus medos sem fantasias - no caso, a do heroísmo, presente no imaginário do protagonista. O maior medo do personagem é encontrar o seu íntimo e encontrar a sua verdade. É o processo pelo qual passa quando, aos trinta anos, retorna à Esplanada, transita por suas ruas e defende o menino desconhecido da gangue. É essa consciência que o faz interromper uma viagem planejada e retornar ao passado, buscando resolver questões pendentes. Parece, então que se fecha um ciclo, pois o Hermano que não evitou a morte do seu melhor amigo salva um desconhecido. A partir daí, ele pode se redimir da covardia que pensa ter protagonizado no passado.

A cidade e o bairro Esplanada são hostis para Hermano, porque evocam a memória de sua vida passada e dos acontecimentos vivenciados, convocando-o a encontrar-se por meio da memória com o que é da ordem do vivido e faz sentido para ele. Bauman que a vivência da cidade como "terra hostil" no que tange à identidade se dá porque "as cidades são campos de batalha nos quais os poderes globais e os sentidos e identidades tenazmente se encontram, se confrontam e lutam, tentando chegar a uma solução satisfatória ou pelo menos aceitável para esse conflito.” (BAUMAN, 2009, p. 35). A resolução desse conflito, segundo ele, pode levar a uma paz duradoura, mas também reorganizar o combate.

A fantasia do heroísmo se concretiza pela defesa do menino espancado em Porto Alegre, no bairro Esplanada, quando ele já tinha trinta anos. Essa ação configura-se como uma espécie de perdão que o protagonista concede a si mesmo por ter agido inadequadamente no passado em relação à morte de Bonobo. Passa a aceitar-se como é, sem mais espelhar-se no outro. Hermano depara-se, então, no encontro consigo mesmo, com o confronto entre a sua identidade local, ou seja, "Mãos de Cavalo" , como é conhecido no Bairro Esplanada, e a identidade de "homem do mundo" que incorporou como um homem que viaja para diferentes partes do planeta com o amigo Renan para escalar.

O Heroísmo e o desafio maiores, enfrentados por ele no encontro consigo mesmo e na busca de sua identidade, vêm sempre atrelados às ruas de Porto Alegre, e na expiação de suas culpas, estruturadas pelo retorno ao Bairro, ao passado e à sua identidade local. Esse processo perpassa os níveis gradativos de afastamento do "cosmos" de Esplanada: espacial, temporal, memorialístico e, finalmente, o nível da tomada de consciência, que possibilitou o seu encontro consigo mesmo, sem fantasias. 


\section{Referências}

BAUMAN, Zygmunt. Identidade: entrevista a Benedetto Vechi. Trad: Carlos Alberto Medeiros. Rio de Janeiro: Jorge Zahar Ed, 2005.

.Confiança e medo na cidade. Rio de Janeiro: Jorge Zahar Ed., 2009.

GALERA, Daniel. Mãos de cavalo. São Paulo: Companhia das Letras, 2006.

MONTENEGRO, Antonio Torres. História oral e memória: a cultura popular revisitada.6 ed. São Paulo: Contexto, 2007.

ORLANDI, Eni. Cidade Atravessada: os sentidos públicos no espaço urbano. Campinas, SP: Pontes, 2001. 